\title{
Arterial infusion of cisplatin plus S-1 against unresectable intrahepatic cholangiocarcinoma
}

\author{
Tokio Higaki, Osamu Aramaki*, Masamichi Moriguchi, Hisashi Nakayama, \\ Yutaka Midorikawa, Tadatoshi Takayama
}

Department of Digestive Surgery, Nihon University School of Medicine, Itabashi-ku, Tokyo, Japan.

\begin{abstract}
Summary Conventional regimens for unresectable intrahepatic cholangiocarcinoma are considered of limited effectiveness. To evaluate the efficacy and toxicity of combination chemotherapy with hepatic arterial infusion of IA-call (a fine-powder formulation of cisplatin) plus oral S-1 in patients with unresectable intrahepatic cholangiocarcinoma. The clinicopathological data and long-term outcome of 12 patients who were received with IA-call plus S-1 were compared with those of 16 patients who were received other treatments, such as radiation therapy, trans-arterial chemoembolization, and systemic chemotherapy. The IA-call plus S-1 regimen consisted of IA-call $\left(65 \mathrm{mg} / \mathrm{m}^{2}\right.$, administered into the hepatic artery) on day 1 and oral S-1 $\left(60 \mathrm{mg} / \mathrm{m}^{2} /\right.$ day) on days $1-28$, every 42 days, repeated cycle. Prognostic factors of these patients were evaluated by uni- and multivariate analysis. There was no significant difference between the two groups in the disease status, such as the number of tumor and the tumor size. The overall survival was significantly longer in the patients receiving the arterial IA-call and S-1 regimen (median survival time $=10.1$; range, 3.6-24.2 months) than in the receiving other treatments (median survival time $=4.0$; range; 0.3-24.2 months, $p=0.01$ ). The multivariate analysis revealed that chemotherapy regimen was significantly related to survival, with a hazard ratio of $3.97(p=0.02)$. In the IA-call plus S-1 group, the overall response rate was $33.3 \%$. The major toxic effect was grade 3 anemia, occurring in 1 patient (4.5\%). Combination chemotherapy with arterial IA-call plus oral S-1 is an effective regimen that may improve survival in patients with unresectable intrahepatic cholangiocarcinoma.
\end{abstract}

Keywords: Arterial infusion chemotherapy, IA-call

\section{Introduction}

Although surgical resection is the only potentially curative treatment for intrahepatic cholangiocarcinoma (ICC), the resectability rate is about $30 \%(1,2)$. Moreover, the 5-year survival rate is $20 \%$ to $40 \%$ after potentially curative resection, accompanying by the high recurrence rate about $50 \%(1,2)$. Systemic chemotherapy is indicated for patients with unresectable disease, however, a standard regimen has yet to be established (3). Various studies of chemotherapy for ICC have suggested that fluoropyrimidine-

*Address correspondence to:

Dr. Osamu Aramaki, Department of Digestive Surgery, Nihon University School of Medicine, 30-1 Ohyaguchikami-machi, Itabashi-ku, Tokyo 173-8610, Japan.

E-mail: takayama.tadatoshi@nihon-u.ac.jp based regimens are promising (4). S-1 (TS-1, Taiho Pharmaceutical Co., Ltd., Tokyo, Japan) is a novel oral fluoropyrimidine preparation combining tegafur, gimeracil, and oteracil potassium. In phase II studies of S-1 monotherapy in patients with biliary tract cancer, the response rate ranged from $21 \%$ to $35 \%$, with median overall survival of 8.3 to 9.4 months $(5,6)$. Fluoropyrimidines are known to act synergistically with cisplatin (7). A phase II study of S-1 and intravenous cisplatin reported a response rate of $30 \%$ and median overall survival of 8.7 months in patients with biliary tract cancer (8). Chemotherapy delivered by transcatheter hepatic arterial infusion (TAI) is a particularly promising, minimally invasive treatment for unresectable liver tumors (9).

We conducted a pilot study to examine the safety and effectiveness of TAI using cisplatin plus oral S-1 in patients with inoperable unresectable ICC. 


\section{Patients and Methods}

\subsection{Patients}

Between 2007 and 2011, we studied 28 patients with unresectable ICC. From April 2010 through December 2011, 12 of these patients received TAI using a finepowder formulation of cisplatin (IA-call) plus oral S-1 (IA-call plus S-1 group). From April 2007 through March 2010, the other 16 patients (other treatment group) received various conventional treatments. Two patients were given radiation therapy, 1 received trans-arterial chemoembolization (TACE) with epirubicine, and 13 were treated with various regimens of chemotherapy. Six patients received intravenous gemcitabine (GEM, $1000 \mathrm{mg} / \mathrm{m}^{2}$ weekly), 1 received a combination of intravenous cisplatin, epirubicin, and 5-fluorouracil (5FU), and 6 received TAI of IA-call (4 in combination with a daily 24-hour continuous intravenous infusion of 5-FU 1,000 mg/m²/day, and 2 without 5-FU). Since April 2010, we have changed our strategy in the treatment of unresectable ICC, and the IA-call plus oral S-1 therapy has been applied from this time. In this study, all the patients with unresectable ICC were divided into two groups at the time of changing the treatment strategy.

A diagnosis of ICC was based on either histopathological or radiologic findings. All patients were deemed unresectable upon exploration due to the locally advanced, intrahepatic and bilateral dissemination, or distant metastases. All patients had good performance status (Eastern Cooperative Oncology Group (ECOG) performance status, 0-2), adequate liver function (bilirubin level $<2.0 \mathrm{mg} / \mathrm{dL}$ ), adequate hematologic and bone marrow function (leukocyte count $>4,000 / \mathrm{uL}$, platelet count $>100,000 / \mu \mathrm{L})$, adequate renal function (creatinine level $<2.0 \mathrm{mg} / \mathrm{dL}$ ), and measurable disease on computed tomography or magnetic resonance imaging. In addition, all patients could undergo angiography and selective visceral catheterization. Patients with biliary obstruction underwent endoscopic retrograde cholangiopancreatography-based or percutaneous transhepatic biliary drainage before administration of TAI and were required to have serum bilirubin levels of $<2.0 \mathrm{mg} / \mathrm{dL}$. All the treatments were started soon after the definite diagnosis.

\subsection{Treatment schedule}

IA-call $^{\circledR}$ (cisplatin $100 \mathrm{mg} / \mathrm{vial}, 1.43 \mathrm{mg} / \mathrm{mL}$; Nippon Kayaku Co., Ltd., Tokyo, Japan;) was dissolved in $70 \mathrm{~mL}$ of saline, heated to $50^{\circ} \mathrm{C}$. A dose of $65 \mathrm{mg} / \mathrm{m}^{2}$ cisplatin was then infused into the hepatic artery at a rate of $2 \mathrm{~mL} / \mathrm{min}$. on day 1 of each cycle. A catheter was placed in the femoral artery and introduced into the hepatic artery under angiographic guidance. After the procedure patients were observed overnight to manage pain and nausea, patients were routinely discharged home the following morning after evaluation of the results of laboratory studies.

S-1 was administered orally at a dose of $60 \mathrm{mg} / \mathrm{m}^{2}$ per day according to body-surface area $\left(<1.25 \mathrm{~m}^{2}, 80 \mathrm{mg}\right.$ daily; $\geq 1.25 \mathrm{~m}^{2}$ to $<1.5 \mathrm{~m}^{2}, 100 \mathrm{mg}$ daily; and $\geq 1.50$ $\mathrm{m}^{2}, 120 \mathrm{mg}$ daily), divided into two doses. S-1 was given on days 1-28, every 42 days. This cycle was repeated if patients had recovered sufficiently from any drug-related toxicity. If patients had hematologic toxicity of grade 3 or higher or non-hematologic toxicity of grade 2 or higher, treatment was postponed until the toxicity subsided to grade 1 or lower.

\subsection{Follow-up and toxicity assessment}

After discharge, laboratory values were checked weekly on an outpatient basis. All patients underwent follow-up imaging studies 6 to 8 weeks after each TAI procedure. Tumor response was assessed according to the Response Evaluation Criteria in Solid Tumors (10). In addition, serum carcinoembryonic antigen and CA19-9 levels were measured and included in the evaluation of therapeutic efficacy. Toxicity was evaluated using the National Cancer Institute Common Toxicity Criteria version 4.0.

\subsection{Statistical analysis}

Overall survival was calculated from the date of the first day of treatment to the date of death from any cause. Survival data were analysed using the KaplanMeier method. The statistical significance of differences between survival curves was determined with the logrank test. Univariate analysis was performed using chi-square tests. Multivariate analysis was performed with a Cox proportion-hazards model. Differences with $p$-values of $<0.05$ were considered statistically significant. All analyses were performed using IBM SPSS Statistics 19 software (IBM SPSS, Tokyo, Japan).

\section{Results}

Twelve patients (median age 76 years [range: 61-83]) received a combination of hepatic arterial infusion of IA call plus oral S-1, and 16 (median age 67 years [5779]) received conventional treatments (Table 1). There was no significant difference between the two groups in the disease status, such as the number of tumor and the tumor size (Table 1).

The median follow-up period for IA call plus S-1 and other treatment group were 10.1 (range 3.6-24.2 months) and 5.8 (range 1.5-24.2 months), respectively. A median of 4 cycles of IA-call plus S-1 (range, 2-9) were administered (Table 2). All of the 12 patients in the IA-call plus S-1 group completed 2 or more courses of chemotherapy. Three patients underwent surgery and had recurrent disease. Intrahepatic recurrence occurred in all the patients, and 1 patient also had 
multiple lung metastases. Eight patients are still alive, and 4 died of tumor progression 4.3 to 11.1 months after initial treatment. No patient had a complete response (CR), 4 (33.3\%) had partial responses (PR), 2 $(16.6 \%)$ had stable disease (SD), and the other $6(50 \%)$ had progressive disease (PD). All of the patients had decreased levels of the tumor marker CA-19-9.

About toxicity in these patients (Table 3), only one patient (4.5\%) had grade 3 anemia, and nonhematologic toxicity was generally mild, including nausea and vomiting. There was no treatment-related death. One patient was refused further chemotherapy because of toxicity (patient No. 1). All patients in the other treatment group died of tumor progression.

The overall survival was significantly longer in patients receiving TAI of IA-call plus S-1 (median

Table 1. Characteristics of patients with unresectable intrahepatic cholangiocarcinoma

\begin{tabular}{|c|c|c|c|c|}
\hline Items & Total & IA call+S-1 & Other & $p$ value \\
\hline No. of patients & 28 & $12(42.8 \%)$ & $16(57.1 \%)$ & \\
\hline \multicolumn{5}{|l|}{ Age (year) } \\
\hline Median [Range] & $73[57-83]$ & $76[61-83]$ & $67[57-79]$ & 0.13 \\
\hline$>65$ & $19(67.9 \%)$ & $10(88.3 \%)$ & $9(56.3 \%)$ & \\
\hline \multicolumn{5}{|l|}{ Gender } \\
\hline Male & $19(67.9 \%)$ & $8(66.7 \%)$ & $11(68.8 \%)$ & 0.9 \\
\hline Female & $9(32.1 \%)$ & $4(33.3 \%)$ & $5(31.3 \%)$ & \\
\hline \multicolumn{5}{|l|}{$\mathrm{ECOG}^{\mathrm{a}}$ performance status } \\
\hline 0 & $23(82.1 \%)$ & $10(83.3 \%)$ & $13(81.3 \%)$ & 0.89 \\
\hline 1 & $5(17.9 \%)$ & $2(16.7 \%)$ & $3(18.8 \%)$ & \\
\hline \multicolumn{5}{|l|}{ Disease status } \\
\hline Solitary & $18(64.3 \%)$ & $7(58.3 \%)$ & $11(68.8 \%)$ & 0.57 \\
\hline Multiple & $10(35.7 \%)$ & $5(41.7 \%)$ & $5(31.3 \%)$ & \\
\hline Tumor size $>5 \mathrm{~cm}$ & $21(75.0 \%)$ & $8(66.7 \%)$ & $13(81.3 \%)$ & 0.38 \\
\hline Vascular invasion & $14(50.0 \%)$ & $4(33.3 \%)$ & $10(62.5 \%)$ & 0.13 \\
\hline Distant metastasis & $10(35.7 \%)$ & $5(41.7 \%)$ & $5(31.3 \%)$ & 0.57 \\
\hline Lymph node metastasis & $7(25.0 \%)$ & $4(33.3 \%)$ & $3(18.8 \%)$ & 0.38 \\
\hline $\mathrm{CEA}^{\mathrm{b}}>\mathrm{ULN}^{\mathrm{c}}$ & $10(35.7 \%)$ & $2(16.7 \%)$ & $8(50.0 \%)$ & 0.07 \\
\hline $\mathrm{CA}_{19-9}>\mathrm{ULN}^{\mathrm{c}}$ & $24(85.7 \%)$ & $9(75.0 \%)$ & $15(93.8 \%)$ & 0.16 \\
\hline
\end{tabular}

${ }^{\mathrm{a}}$ Eastern Cooperative Oncology Group. ${ }^{\mathrm{b}}$ Carcinoembryonic antigen. ${ }^{\mathrm{c}}$ Upper limit of normal.

Table 2. Characteristics of the patients treated with IA call and S-1

\begin{tabular}{|c|c|c|c|c|c|c|}
\hline $\begin{array}{l}\text { Patient } \\
\text { No. }\end{array}$ & Age & $\begin{array}{l}\text { Maximum } \\
\text { response }\end{array}$ & $\begin{array}{l}\text { Liver } \\
\text { resection }\end{array}$ & $\begin{array}{c}\text { Cycles of } \\
\text { IA-call }+ \text { S-1 }\end{array}$ & $\begin{array}{l}\text { Highest CA 19-9 } \\
\text { before therapy }(\mathrm{U} / \mathrm{mL})\end{array}$ & $\begin{array}{c}\text { Lowest CA 19-9 } \\
\text { after therapy }(\mathrm{U} / \mathrm{mL})\end{array}$ \\
\hline 1 & 83 & PD & Absent & 2 & 381 & 76.3 \\
\hline 2 & 77 & PD & Absent & 3 & 102.8 & 79.3 \\
\hline 3 & 75 & PR & Absent & 5 & 398.2 & 51.1 \\
\hline 4 & 76 & SD & Absent & 5 & 140.7 & 33.9 \\
\hline 5 & 64 & PD & Absent & 4 & $>1,000,000$ & 198,900 \\
\hline 6 & 81 & PR & Absent & 5 & 59.2 & 5.9 \\
\hline 7 & 74 & SD & Absent & 9 & 42.5 & 12.9 \\
\hline 8 & 67 & PD & Absent & 4 & 4.5 & 2.9 \\
\hline 9 & 81 & PD & Present & 5 & 26.4 & 6.4 \\
\hline 10 & 74 & PR & Present & 3 & 277.5 & 88.2 \\
\hline 11 & 61 & PR & Absent & 3 & 131,800 & 42,230 \\
\hline 12 & 77 & SD & Present & 3 & 47.7 & 20.9 \\
\hline
\end{tabular}

PD: Progressive disease, PR: Partial response, SD: Stable disease

Table 3. Toxicity in patients receiving the arterial infusion of IA-call and S-1

\begin{tabular}{|c|c|c|c|c|c|}
\hline Toxicity profile $(n=22)$ & Grade 1 & Grade 2 & Grade 3 & Grade 4 & Grade 3-4 (\%) \\
\hline \multicolumn{6}{|l|}{ Hematologic } \\
\hline Leukopenia & 1 & 5 & 0 & 0 & 0 \\
\hline Neutropenia & 1 & 5 & 0 & 0 & 0 \\
\hline Anemia & 4 & 5 & 1 & 0 & $1(4.54 \%)$ \\
\hline Thrombocytopenia & 3 & 2 & 0 & 0 & 0 \\
\hline \multicolumn{6}{|l|}{ Non-hematologic } \\
\hline Nausea & 2 & 3 & 0 & 0 & 0 \\
\hline Vomiting & 1 & 1 & 0 & 0 & 0 \\
\hline
\end{tabular}

National Cancer Institute Common Toxicity Criteria Version 4.0 


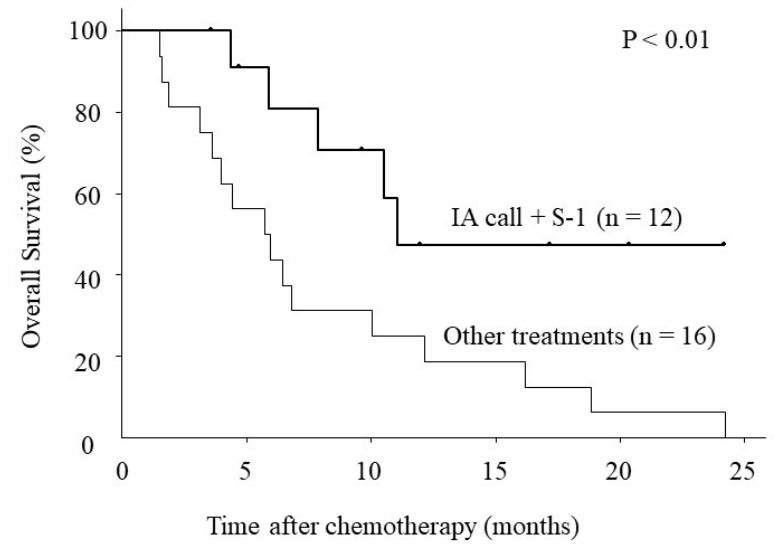

Figure 1. Overall survival of patients receiving the transarterial infusion of IA-call and S-1 regimen vs. those receiving other treatments. The overall survival was significantly longer in patients receiving transarterial infusion of IA-call plus S-1 (median survival time $=10.1$; range, 3.6-23.2 months) than in those receiving other treatments (median survival time $=4.0$; range; 0.3-24.2 months) $(P<0.01)$.

survival time $=10.1$; range, $3.6-23.2)$ than in those receiving other treatments (median survival time $=4.0$; range; 0.3-24.2; Figure $1 ; p<0.01)$.

To determine the prognostic factors on survival in patients with unresectable ICC, univariate analyses were conducted (Table 4). The results of univariate analysis indicated that two variables, age and type of treatment, significantly affected the patients' overall survival (Table 4). Cox's proportional-hazard analysis including 3 variables (age, tumor size, and type of treatment) showed that only the type of treatment (IA call + S-1 vs. Other treatment, hazard ratio 3.97; $95 \%$ CI 1.28-12.3, $p=0.02$ ) was an independent risk factor for overall survival.

\section{Discussion}

In this study, we evaluated the efficacy and toxicity of TAI using cisplatin plus oral S-1 in patients with unresectable ICC. Our results showed that overall survival was significantly longer in patients receiving TAI of IA-call plus S-1 (median survival time $=10.1$; range, 3.6-23.2) than in those receiving other treatments (median survival time $=4.0$; range; $0.3-24.2 ; p<$ $0.01)$. Moreover, IA-call plus S-1 was associated with moderate toxicity, with grade 3 anemia occurring in only 1 patient $(4.5 \%)$.

Although systemic chemotherapy is indicated for unresectable ICC, conventional regimens are considered of limited effectiveness. There is an acute need for new treatment approaches. We used TAI of IA-call and S-1 to treat unresectable ICC for several reasons. ICC can extend in a multimodal and locoregional manner by means of infiltration of the parenchyma, the formation of intrahepatic satellite nodules, and vascular invasion (11). The remnant liver is the most common site of recurrence $(12,13)$. To prevent ICC from extending to
Table 4. Univariate analysis of prognostic factors of overall survival

\begin{tabular}{|c|c|c|c|}
\hline Items & Hazard ratio & $\begin{array}{l}95 \% \text { Confidence } \\
\text { interval }\end{array}$ & $p$ value \\
\hline \multicolumn{4}{|l|}{ Gender } \\
\hline \multicolumn{4}{|l|}{ Male } \\
\hline Female & 0.56 & $0.20-1.59$ & 0.28 \\
\hline \multicolumn{4}{|l|}{ Age } \\
\hline \multicolumn{4}{|l|}{$\leq 64$} \\
\hline$>65$ & 2.82 & $1.09-7.27$ & 0.03 \\
\hline \multicolumn{4}{|l|}{ Tumor size } \\
\hline \multicolumn{4}{|l|}{$\leq 5$} \\
\hline$>5$ & 2.79 & $0.81-9.66$ & 0.11 \\
\hline \multicolumn{4}{|l|}{ Vascular invasion } \\
\hline \multicolumn{4}{|l|}{ Absent } \\
\hline Present & 2.08 & $0.83-5.23$ & 0.12 \\
\hline \multicolumn{4}{|c|}{ Lymph node metastasis } \\
\hline \multicolumn{4}{|c|}{ Absent } \\
\hline Present & 1.45 & $0.55-4.04$ & 0.48 \\
\hline \multicolumn{4}{|l|}{ Number of tumors } \\
\hline \multicolumn{4}{|l|}{ Solitary } \\
\hline Multiple & 2.18 & $0.79-5.99$ & 0.13 \\
\hline \multicolumn{4}{|l|}{ CA19-9 } \\
\hline \multicolumn{4}{|l|}{$<\mathrm{ULNa}$} \\
\hline$>\mathrm{ULNa}$ & 2.04 & $0.47-8.92$ & 0.34 \\
\hline \multicolumn{4}{|l|}{ Treatment } \\
\hline IA call + S-1 & & & \\
\hline Other treatment & 4.21 & $1.40-12.63$ & 0.01 \\
\hline
\end{tabular}

${ }^{a}$ Upper limit of normal.

the lymph nodes or other organs via vascular invasion, systemic chemotherapy might be useful. To date, the most promising approaches have used single-agent GEM. Median survival times of 14 months and 11 months have been obtained with combinations of GEM plus capecitabine (14) and GEM plus docetaxel (15), respectively. However, the therapeutic usefulness of these GEM-based combined regimens in patients with unresectable ICC has been limited by toxicity (16). In contrast, recent phase 2 trials of S-1 monotherapy in patients with biliary tract cancer have obtained high response rates with mild toxicity $(5,6)$. Therefore, we selected S-1 for systemic chemotherapy to prevent the spread of ICC to lymph nodes or other organs.

TAI allows the delivery of high doses of chemotherapeutic drugs directly to tumors, with minimal systemic drug exposure. Consequently, techniques for TAI-based chemotherapy have been developed to achieve higher therapeutic efficacy than that possible with intravenous administration of anticancer agents. With TAI, an anticancer agent is infused into an artery supplying the target tumor, thereby producing high drug concentrations at the target site in the liver. Because the blood supply of the biliary tree is derived from the hepatic artery, and ICC is usually confined to the liver, TAI might be a rational approach. To prevent the spread of ICC in the liver, TAI-based chemotherapy is considered promising (17). Moreover, to obtain higher drug concentrations than those produced by conventional formations of cisplatin 
$(0.5 \mathrm{mg} / \mathrm{mL})$, we used IA-call $(1.43 \mathrm{mg} / \mathrm{mL})$, a finepowder formulation of cisplatin (9). To our knowledge, only a few studies have evaluated the effectiveness of hepatic arterial chemotherapy in patients with biliary tract carcinomas such as ICC. Melichar et al. treated 17 patients with ICC and 15 with gallbladder carcinoma with a combination of 5-FU, cisplatin, and folinic acid, administered through the hepatic artery. This regimen was effective and improved survival (18). Cantore et al. gave 25 patients with ICC and 5 with gallbladder carcinoma a combination of epirubicin and cisplatin administered through the hepatic artery plus a systemic infusion of 5-FU. The overall response rate was $40 \%$, with median overall survival of 13.2 months (19). Kelsen et al. reported that the administration of cisplatin through the hepatic artery provides a high drug concentration in the perfused blood, whereas the systemic concentration is much lower (20). The few side effects with IA-call plus S-1 may thus be attributed by the lower systemic exposure to cisplatin.

Combination chemotherapy with arterial IA-call plus oral S-1 might have a higher risk of some complications than conventional systemic chemotherapy. Angiography is generally a very safe procedure, and of the 12 patients, no complications related to the angiographic technique were observed. However, there is a small chance of minor or serious complications occurring, such as hemorrhage, arterial obstruction, and pseudoaneurysms (21). To prevent these complications, we try to do the examination as patriotically as possible.

In conclusion, this pilot study suggests that TAI of IA-call plus S-1 is a safe and effective regimen. Our promising initial results warrant further phase II and III trials to confirm the feasibility and efficacy of IA-call plus S-1 in patients with unresectable ICC.

\section{Acknowledgements}

This work was mainly supported by a Grant-in-Aid for Scientific Research (A) 24249068 from the Ministry of Education, Culture, Sports, Science and Technology (MEXT), Japan.

\section{References}

1. Ohtsuka M, Ito H, Kimura F, Shimizu H, Togawa A, Yoshidome H, Miyazaki M. Results of surgical treatment for intrahepatic cholangiocarcinoma and clinicopathological factors influencing survival. Br J Surg. 2002; 89:1525-1531.

2. Khan SA, Davidson BR, Goldin R, Pereira SP, Rosenberg WM, Taylor-Robinson SD, Thillainayagam AV, Thomas HC, Thursz MR, Wasan H; British Society of Gastroenterology. Guidelines for the diagnosis and treatment of cholangiocarcinoma: Consensus document. Gut. 2002; 51 Suppl 6:VI1-9.

3. Glimelius B, Hoffman K, Sjödén PO, Jacobsson G, Sellström H, Enander LK, Linné T, Svensson C.
Chemotherapy improves survival and quality of life in advanced pancreatic and biliary cancer. Ann Oncol. 1996; 7:593-600.

4. Mazhar D, Stebbing J, Bower M. Chemotherapy for advanced cholangiocarcinoma: What is standard treatment? Future Oncol. 2006; 2:509-514.

5. Ueno H, Okusaka T, Ikeda M, Takezako Y, Morizane C. Phase II study of S-1 in patients with advanced biliary tract cancer. Br J Cancer. 2004; 91:1769-1774.

6. Furuse J, Okusaka T, Boku N, Ohkawa S, Sawaki A, Masumoto T, Funakoshi A. S-1 monotherapy as firstline treatment in patients with advanced biliary tract cancer: A multicenter phase II study. Cancer Chemother Pharmacol. 2008; 62:849-855.

7. Shirasaka T, Shimamoto Y, Ohshimo H, Saito H, Fukushima M. Metabolic basis of the synergistic antitumor activities of 5 -fluorouracil and cisplatin in rodent tumor models in vivo. Cancer Chemother Pharmacol. 1993; 32:167-172.

8. Kim YJ, Im SA, Kim HG, et al. A phase II trial of S-1 and cisplatin in patients with metastatic or relapsed biliary tract cancer. Ann Oncol. 2008; 19:99-103.

9. Yoshikawa M, Ono N, Yodono H, Ichida T, Nakamura H. Phase II study of hepatic arterial infusion of a fine-powder formulation of cisplatin for advanced hepatocellular carcinoma. Hepatol Res. 2008; 38:474483.

10. Therasse P, Arbuck SG, Eisenhauer EA, Wanders J, Kaplan RS, Rubinstein L, Verweij J, Van Glabbeke M, van Oosterom AT, Christian MC, Gwyther SG. New guidelines to evaluate the response to treatment in solid tumors. European Organization for Research and Treatment of Cancer, National Cancer Institute of the United States, National Cancer Institute of Canada. J Natl Cancer Inst. 2000; 92:205-216.

11. Inoue K, Makuuchi M, Takayama T, Torzilli G, Yamamoto J, Shimada K, Kosuge T, Yamasaki S, Konishi M, Kinoshita T, Miyagawa S, Kawasaki S. Long-term survival and prognostic factors in the surgical treatment of mass-forming type cholangiocarcinoma. Surgery. 2000; 127:498-505.

12. Yamamoto M, Takasaki K, Otsubo T, Katsuragawa $\mathrm{H}$, Katagiri S. Recurrence after surgical resection of intrahepatic cholangiocarcinoma. J Hepatobiliary Pancreat Surg 2001; 8:154-157.

13. Weber SM, Jarnagin WR, Klimstra D, DeMatteo RP, Fong Y, Blumgart LH. Intrahepatic cholangiocarcinoma: Resectability, recurrence pattern, and outcomes. Am Coll Surg 2001; 193:384-391.

14. Knox JJ, Hedley D, Oza A, Feld R, Siu LL, Chen E, Nematollahi M, Pond GR, Zhang J, Moore MJ. Combining gemcitabine and capecitabine in patients with advanced biliary cancer: A phase II trial. J Clin Oncol 2005; 23:2332-2338.

15. Kuhn R, Hribaschek A, Eichelmann K, Rudolph S, Fahlke J, Ridwelski K. Outpatient therapy with gemcitabine and docetaxel for gallbladder, biliary, and cholangio-carcinomas. Invest New Drugs. 2002; 20:351356.

16. Dingle BH, Rumble RB, Brouwers MC; Cancer Care Ontario's Program in Evidence-Based Care's Gastrointestinal Cancer Disease Site Group. The role of gemcitabine in the treatment of cholangiocarcinoma and gallbladder cancer: A systematic review. Can J Gastroenterol. 2005; 19:711-716. 
17. Melichar B, Cerman J Jr, Dvorák J, Jandík P, Mergancová J, Melicharová K, Tousková M, Krajina A, Voboril Z. Regional chemotherapy in biliary tract cancers - A single institution experience. Hepatogastroenterology. 2002; 49:900-906.

18. Vexler AM, Mou X, Gabizon AA, Gorodetsky R. Reduction of the systemic toxicity of cisplatin by intra-arterial hepatic route administration for liver malignancies. Int J Cancer. 1995; 60:611-615.

19. Cantore M, Mambrini A, Fiorentini G, Rabbi C, Zamagni D, Caudana R, Pennucci C, Sanguinetti F, Lombardi M, Nicoli N. Phase II study of hepatic intraarterial epirubicin and cisplatin, with systemic 5-fluorouracil in patients with unresectable biliary tract tumors. Cancer. 2005; 103:1402-1407.

20. Kelsen DP, Hoffman J, Alcock N, Cheng E, Bailey E, Young C, Golbey R, Fortner J. Pharmacokinetics of cisplatin regional hepatic infusions. Am J Clin Oncol. 1982; 5:173-178.

21. Hessel SJ, Adams DF, Abrams HL. Complications of angiography. Radiology. 1981; 138:273-281.

(Received December 26, 2017; Revised February 2, 2018; Accepted February 6, 2018) 